\title{
PENGEMBANGAN BUDIDAYA IKAN HIAS AIR LAUT DENGAN PENGGUNAAN BIOFILTER PADA SISTEM RESIRKULASI
}

\section{Development of Marine Ornamental Fish Cultivation Using Biofilters in Recirculation System}

\author{
Oleh: \\ Ladestam Sitinjak $^{1 *}$, Henry Sinaga ${ }^{2}$ \\ ${ }^{1}$ Laboratorium Perikanan Tangkap, Program Studi \\ Pemanfaatan Sumberdaya Perairan, Sekolah Tinggi \\ Perikanan Sibolga, Sibolga, Indonesia \\ ${ }^{2}$ Program Studi Pemanfaatan Sumberdaya Perikanan, \\ Sekolah Tinggi Perikanan Sibolga, Sibolga, Indonesia \\ *Korespondensi penulis: ladestamsitinjak@stpsibolga.ac.id
}

\begin{abstract}
ABSTRAK
Rendahnya kualitas dan kuantitas budidaya ikan disebabkan salah satunya eksploitasi laut yang terus menerus dilakukan. Penelitian ini bertujuan untuk mengetahui pengaruh penggunaan biofilter pada sistem resirkulasi terhadap kualitas air yang digunakan untuk pengembangan budidaya ikan hias air laut. RAS (Recirculating Aquaculture System) merupakan teknik pengolahan air laut yang memadukan filter biologi dan fisika yang mampu meningkatkan kualitas air. Metode yang dilakukan adalah metode eksperimen dan menggunakan analisis data ANOVA (Analysis of Variant) yang disajikan dalam bentuk sidik ragam dan histogram. Kualitas air dengan sistem resirkulasi biofilter ini tergolong baik, yaitu suhu air $28^{\circ} \mathrm{C}$, salinitas $26 \mathrm{ppm}$ dan kelulushidupan ikan hias air laut $100 \%$.
\end{abstract}

Kata kunci: biofilter, ikan hias air laut, resirkulasi, terumbu karang

\begin{abstract}
Low quality and quantity of fish farming is due to continuous sea exploitation. This study aims to determine the effect of biofilter use in the recirculation system on the quality of water used for development of marine ornamental fish cultivation. RAS (Recirculating Aquaculture System) is seawater treatment technique that combines biological and physical filters that can improve water quality. The method used is an experimental method and uses ANOVA (Analysis of Variant) data analysis which is presented in the form of variance and histograms. Water quality with this biofilter recirculation system is classified as good, namely the water temperature is $28^{\circ} \mathrm{C}$, salinity is $26 \mathrm{ppm}$ and survival rate of marine ornamental fish is $100 \%$.
\end{abstract}

Key words: biofilter, coral reef, recirculation, marine ornamental fish

\section{PENDAHULUAN}

Sumberdaya ikan hias air laut saat ini lebih banyak dieksploitasi untuk perikanan konsumsi tanpa diimbangi dengan teknik penanganan yang mampu meningkatkan nilai jual ikan tersebut. Jika eksploitasi laut terus menerus dilakukan hal ini akan merusak ekosistem laut yang sudah ada. Salah satu biota laut yang banyak dimanfaatkan masyarakat adalah terumbu karang. Menurut Samsul Bahri (2015) suatu wilayah dengan aktifitas lingkungan yang baik serta didukung dengan pengelolaan yang baik akan meningkatkan kesehatan dan produktifitas ekosistem terumbu karang dilingkungan tersebut. Karang digunakan sebagai biofilter dalam akuarium oleh para pembudidaya. Namun saat ini 
dari observasi lapangan menunjukkan perawatan karang masih tergolong sangat rendah yang menyebabkan anemon dan terumbu karang yang diambil dari alam mati dan merusak ekosistem laut.

Jenis terumbu karang yang popular dikalangan penggemar akuarium air laut adalah jenis karang lunak (soft cora). Selama ini para penggemar akuarium dan ikan hias air laut cenderung menggunakan filter yang perawatan serta penanganan yang cukup mahal dan rumit. Namun sistem filter tersebut hanya mampu mempertahan kan anemon dan terumbu karang sekitar 4-6 bulan saja. Setelah lebih dari 6 bulan warna anemon serta terumbu karang akan mulai memudar dan mati maka dari itu anemon dan terumbu karang harus segera diganti agar tidak mengganggu ekosistem di dalam akuarium (Syahrul P, 2015).

Selain itu dalam merawat akuarium sebagai ekosistem laut buatan membutuhkan teknik khusus, perlu adanya sistem yang mampu menjaga dan mempertahankan kualitas air sekaligus umur karang di dalamnya. Sistem resirkulasi merupakan sistem yang memiliki prinsip menggunakan kembali air yang pernah digunakan untuk kegiatan budidaya. Dua komponen penting dalam sistem resirkulasi yaitu adalah budidaya dan filter (Safira RF, 2020). Sistem resirkulasi ini selain terjangkau, aman, serta efektif dalam menyaring partikel-partikel terlarut dalam air. Kualitas air juga dapat dipertahankan, anemon serta terumbu karang hingga satu tahun penggunaan. Proses pengolahan limbah pada sistem resirkulasi dapat berupa filtrasi fisik, filtrasi biologi dan filtrasi kimia (Wahyu I, 2019). Tujuan penelitian ini adalah untuk mengoptimalkan hasil tangkapan dan budidaya ikan hias air laut saat akan dipasarkan kepada konsumen melalui pembuatan resirkulasi dalam usaha pemanfaatan dan budidaya ikan hias air laut.

Hasil penelitian ini diharapkan dapat memberi manfaat secara akademik dan praktis yaitu memberikan sosialisasi berupa seminar kepada nelayan, petani dan pelaku usaha perikanan tentang kegiatan budidaya tanaman dan ikan berbasis sistem resirkulasi akuakultur memberi sumbangsih terhadap perkembangan ilmu pengetahuan berupa publikasi jurnal ilmiah ber-ISSN (nasional terakreditasi), sementara kebaruan dari riset ini adalah teknologi yang digunakan untuk perkembangbiakan ikan hias air laut yang sebelumnya lebih banyak untuk ikan hias air tawar.

\section{METODE PENELITIAN}

Penelitian ini dilaksanakan pada 12 Januari 2020 sampai dengan 22 Oktober 2020 di Laboratorium Perikanan Tangkap Sekolah Tinggi Perikanan Sibolga. Pengumpulan data dilakukan menggunakan metode eksperimen, wawancara serta studi literatur. Penelitian ini dilakukan dalam dua tahap yaitu penelitian pendahuluan yang terdiri dari pembuatan wadah resirkulasi menggunakan filter bio-organic dan filter busa. Penelitian selanjutnya adalah penanganan ikan sampel selama proses penelitian dilakukan. Gambar di bawah menyajikan wadah dan biofilter yang digunakan dalam penelitian ini.

Data yang dibutuhkan dalam penelitian ini yaitu kegiatan uji coba pengendalian kualitas air dengan perlakuan dan kelulushidupan (survival rate) ikan. Fiber pada setiap perlakuan diletakkan pada lokasi yang sama, beberapa data tambahan yang dibutuhkan meliputi jumlah volume air, berat karang, sumber air, perpustakaan serta media elektronik. Data yang diperoleh selanjutnya dianalisis dengan menggunakan ANOVA disajikan dalam bentuk sidik ragam dan histogram sebagai berikut (Sudjana 2018).

$$
Y i j=\mu+\pi i+€ i j
$$

Keterangan:

Yij = nilai pengamatan pengaruh perlakuan filter bio-organic

$\mu \quad=$ nilai tengah perlakuan

$\pi \mathrm{i}=$ pengaruh perlakuan biofilter

$€ \mathrm{ij}=$ pengaruh galat percobaan 
$\mathrm{i} \quad=$ perlakuan busa filter, biofilter

j $\quad=1,2,3$ (ulangan)

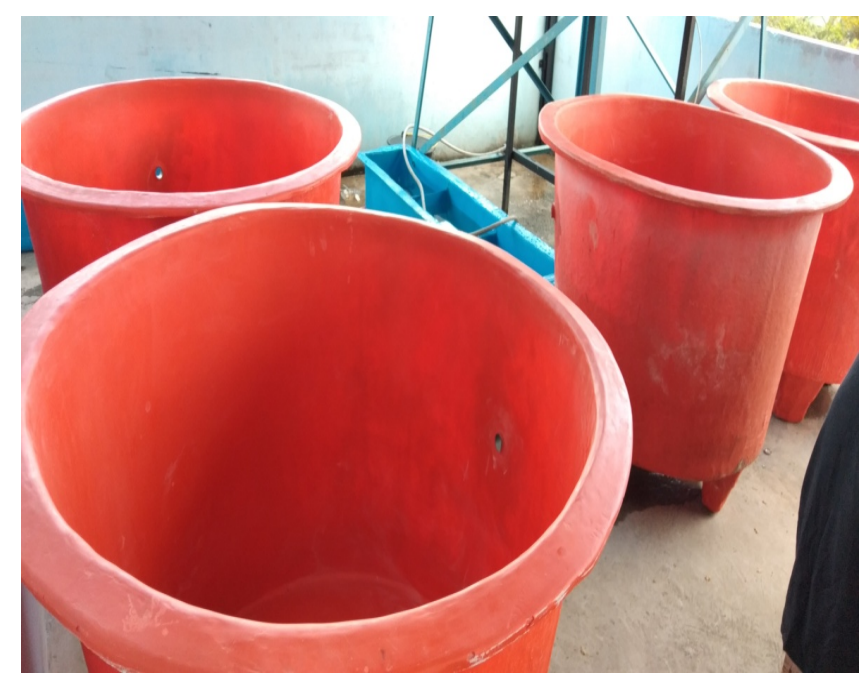

Gambar 1 Wadah Resirkulasi

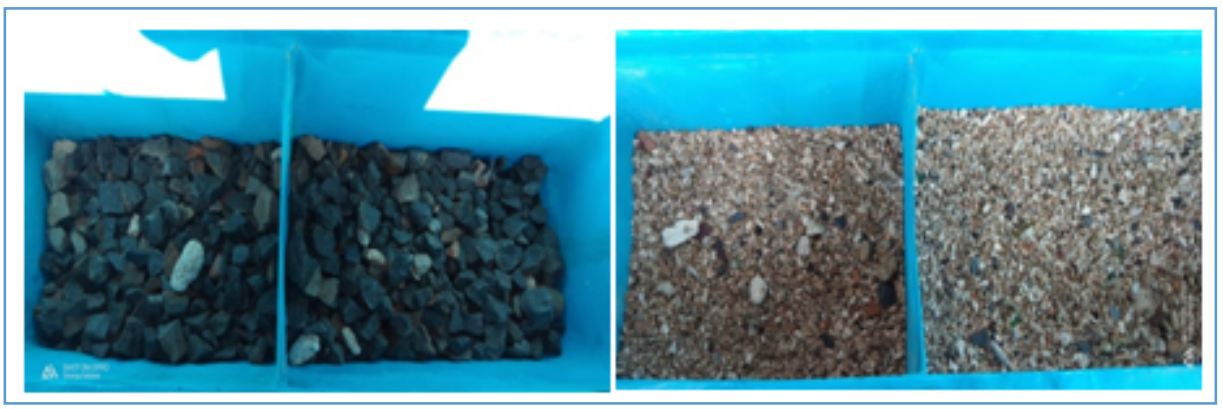

Gambar 2 Biorganik Filter

\section{HASIL DAN PEMBAHASAN}

\section{Rangkaian Resirkulasi}

Rangkaian resirkulasi terdiri dari beberapa tahap mulai dari persiapan alat dan bahan hingga merangkai alat dan bahan menjadi sistem resirkulasi yang kompleks. Berikut adalah tahapan dalam merangkai sistem resirkulasi.

1. Menyiapkan alat dan bahan

Alat dan bahan sistem resirkulasi terdiri dari tabung resirkulasi, fiber filter, filter organik, busa filter, kerikil dan pecahan batu karang serta peralatan pendukung lainnya.

2. Merangkai sistem resirkulasi

Pada tahapan merangkai sistem resirkulasi kita mulai mengisi fiber filter dengan bio-organic filter. Ruang pertama terdiri dari susunan batu kerikil setinngi $10 \mathrm{~cm}$ kemudian dilapis dengan pecahan batu karang setinggi $15 \mathrm{~cm}$. sedangkan pada ruang kedua diisi dengan komposisi yang sama tetapi ketinggian setiap filtrasinya berbeda. Sementara itu pada fiter busa digunakan busa dengan ukuran $30 \times 40 \times 2 \mathrm{~cm}$ sebanyak tiga lapis pada ruang 1 dan 2.

3. Mengisi fiber tank dengan air laut

Pada tahapan ini, filter tank A dan B diisi air laut sebanyak 270 liter. 
4. Memasang rangkaian pipa inlet, outlet serta pompa

Pipa pada rangkaian resirkulasi terdiri dari tiga bagian. Pertama pipa untuk mengalirkan air dari fiber tank A ke filter dengan bantuan pompa resirkulator, kedua mengalirkan air ke fiber tank B dari filter sebagai hasil filtrasi dan kemudian yang ketiga pipa yang menghubungkan fiber tank B ke A untuk nantinya diresirkulasi kembali.

\section{Kualitas Air Fiber Tank}

Suhu

Suhu merupakan parameter lingkungan yang sangat besar pengaruhnya pada hewan akuatik (Sri Samsudari, 2013). Pengamatan terhadap suhu fiber tank yang telah diberikan filter dilakukan untuk melihat apakah perubahan kenaikan suhu dipengaruhi oleh sistem filter air yang ada. Suhu awal air laut saat diambil dari laut berkisar antara $30^{\circ} \mathrm{C}$ sampai $32^{\circ} \mathrm{C}$. Tabel 1 menyajikan suhu air laut pada awal penelitian.

Tabel 1 Pengukuran Suhu Awal Penelitian

\begin{tabular}{lcc}
\hline \multicolumn{1}{c}{ Waktu } & Suhu pada Fiber Tank & Suhu pada Filter Air \\
\hline Pagi & $27^{\circ} \mathrm{C}$ & $27^{\circ} \mathrm{C}$ \\
Siang & $27^{\circ} \mathrm{C}$ & $27^{\circ} \mathrm{C}$ \\
Sore & $27^{\circ} \mathrm{C}$ & $27^{\circ} \mathrm{C}$ \\
\hline
\end{tabular}

Perbandingan suhu awal penelitian pada Tabel 1 menunjukkan pengendapan air laut selama satu hari memberikan suhu yang sama yaitu $27^{\circ} \mathrm{C}$. Pengukuran hasil penelitian ini akan dijadikan pembanding akhir setelah air difiltrasi dengan menggunakan filter bio-organic dan filter busa.

Air laut memiliki suhu yang cenderung lebih tinggi dibandingkan air tawar, ini dikarenakan kerapatan air laut yang lebih tinggi (Mochammad IE, 1979). Tingginya densitas atau massa air laut tentunya dipengaruhi oleh salinitas atau kandungan garam yang ada pada air laut. Semakin tinggi salinitasnya maka akan berbanding lurus terhadap suhu perairan tersebut (Mochammad IE, 2004)

Perhitungan selisih perubahan suhu pada kedua perlakuan penelitian ini dilakukan setelah 10 hari masa filtrasi. Pengukuran suhu ini dilakukan saat pagi, siang dan sore hari agar sama pada waktu pengukuran diawal penelitian (Lesmana 2016). Sebaran data pada pengukuran suhu pada perlakuan 1 dan perlakuan 2 dapat kita lihat pada Tabel 2.

Tabel 2 Pengukuran Suhu setelah Perlakuan Filtrasi

\begin{tabular}{lcc}
\hline \multicolumn{1}{r}{ Waktu } & Suhu pada Fiber Tank & Suhu pada Filter Air \\
\hline Pagi & $27^{\circ} \mathrm{C}$ & $27^{\circ} \mathrm{C}$ \\
Siang & $28^{\circ} \mathrm{C}$ & $28^{\circ} \mathrm{C}$ \\
Sore & $28^{\circ} \mathrm{C}$ & $29^{\circ} \mathrm{C}$ \\
\hline
\end{tabular}

Suhu rata-rata air laut pada fiber tank yang mendapat perlakuan filter busa sekitar $28^{\circ} \mathrm{C}$ dan suhu rata-rata pada filter bio-organic sekitar $28^{\circ} \mathrm{C}$. Pada nilai perbandingan ini menunjukkan tidak ada pengaruh penggunaan filter yang berbeda terhadap suhu pada kedua tank. Hasil penelitian Muhammad et al. (2017) juga menyampaikan hal yang sama, suhu air pada wadah pemeliharaan ikan mas koki berkisar antara $25,7^{\circ} \mathrm{C}-29,7^{\circ} \mathrm{C}$ dengan menggunakan filter ijuk, jerami padi dan ampas tebu. Bila ada perubahan suhu disetiap harinya kemungkinan hal itu dipengaruhi oleh faktor lingkungan serta organisme yang hidup didalamnya.

\section{Salinitas}

Dalam penelitian ini, pengukuran salinitas dilakukan dalam tiga tahapan tujuannya untuk mengukur jumlah kadar garam setelah mengalami filtrasi. Salinitas perairan menjadi salah satu parameter yang diukur karena ikan yang dipelihara merupakan ikan hias air laut yang membutuhkan 
salinitas tertentu. Salinitas air laut yang diolah dianggap memiliki nilai awal yang sama karena berasal dari daerah perairan yang sama.

Hasil pengukuran salinitas air yang belum mengalami proses penyaringan pada saat awal penelitian dapat dilihat pada Tabel 3. Data pengukuran menunjukkan bahwa salinitas air dari awal penelitian memiliki nilai yang sama yaitu $26 \mathrm{ppm}$. Salinitas air laut ini sangat dipengaruhi oleh jarak sumber pengambilan sampel dari garis pantai, suhu air pada saat pengambilan sampel dan proses pasang surut. Pengambilan sampel dilakukan pada pagi hari dimana suhu perairan pada saat itu berkisar $28^{\circ} \mathrm{C}$.

Tabel 3 Pengukuran Salinitas Air pada Awal Penelitian.

\begin{tabular}{lcc}
\hline \multicolumn{1}{c}{ Waktu } & Salinitas pada Fiber Tank & Salinitas pada Filter Air \\
\hline Pagi & $26 \mathrm{ppm}$ & $26 \mathrm{ppm}$ \\
Siang & $26 \mathrm{ppm}$ & $26 \mathrm{ppm}$ \\
Sore & $26 \mathrm{ppm}$ & $26 \mathrm{ppm}$ \\
\hline
\end{tabular}

Pengukuran salinitas air pada awal penelitian berkisar 26 ppm pada kedua perlakuan. Pantai barat Sumatera merupakan perairan terbuka yang di sekitarnya terdapat beberapa aliran anak sungai. Rendahnya salinitas disekitar pelabuhan tentunya sangat dipengaruhi oleh aliran anak sungai dan sedimentasi dasar perairan akibat daerah aliran sungai (Thesiana 2015).

Selain aliran sungai perubahan salinitas juga sangat dipengaruhi oleh limbah dari sampah organik yang masuk menuju lautan. Seperti yang kita ketahui bahwa sepanjang garis pantai Sibolga banyak ditemukan rumah panggung dan pelabuhan swasta yang berada di atas permukaan laut. Tabel 4 menyajikan hasil pengukuran salinitas pada akhir penelitian.

Tabel 4. Pengukuran Salinitas pada Akhir Penelitian

\begin{tabular}{lcc}
\hline \multicolumn{1}{c}{ Waktu } & Salinitas pada Fiber Tank & Salinitas pada Filter Air \\
\hline Pagi & $26 \mathrm{ppm}$ & $26 \mathrm{ppm}$ \\
Siang & $27 \mathrm{ppm}$ & $28 \mathrm{ppm}$ \\
Sore & $27 \mathrm{ppm}$ & $28 \mathrm{ppm}$ \\
\hline
\end{tabular}

Pengaruh Filter Organik

Penggunaan filter organik pada penelitian ini dimaksudkan untuk meningkatkan kualitas air dan memperpanjang masa pergantian air. Kita ketahui bahwa kendala utama dalam pemeliharaan ikan hias air laut adalah pergantian air yang sulit karena sangat mempengaruhi metabolisme organisme didalamnya, perubahan suhu dan air secara tiba-tiba dapat menyebabkan stres bahkan kematian pada organisme peliharaan.

Hasil penelitian menunjukkan bahwa penggunaan filter organik tidak hanya membantu para penggemar ikan hias air laut dalam melakukan pengeloaan air tetapi mampu menjadi suplemen tambahan dari zat renik yang tumbuh serta melekat pada batuan koral. Proses biologis terjadi karena adanya mikroorganisme-mikroorganisme yang menempel pada permukaan media yang dikenal dengan nama schmutzdecke ( Chandra TF, 2012). Ada dua jenis pengamatan secara visual yang dilakukan pada penelitian ini yaitu kelulusan hidup ikan dan kualitas air.

\section{Kelulushidupan Ikan Hias}

Sampel ikan yang menjadi objek pada penelitian ini adalah ikan clownfish, yang diperoleh dari Pantai Pandan, Tapanuli Tengah. Ikan ini merupakan hasil tanggkapan nelayan tradisional yang disediakan pengepul ikan hias air laut di Kota Pandan. Ukuran ikan yang digunakan sebanyak 15 ekor tiap perlakuaannya, dengan panjang 1-2 $\mathrm{cm}$ dan berat total 23 gr. Pemeliharaan ikan dilakukan selama 30 hari dengan memberikan daging udang sebagai pakan tambahan (Widyantoroet al. 2014). Gambar 3 menyajikan kelulushidupan (survival rate) ikan objek penelitian. 


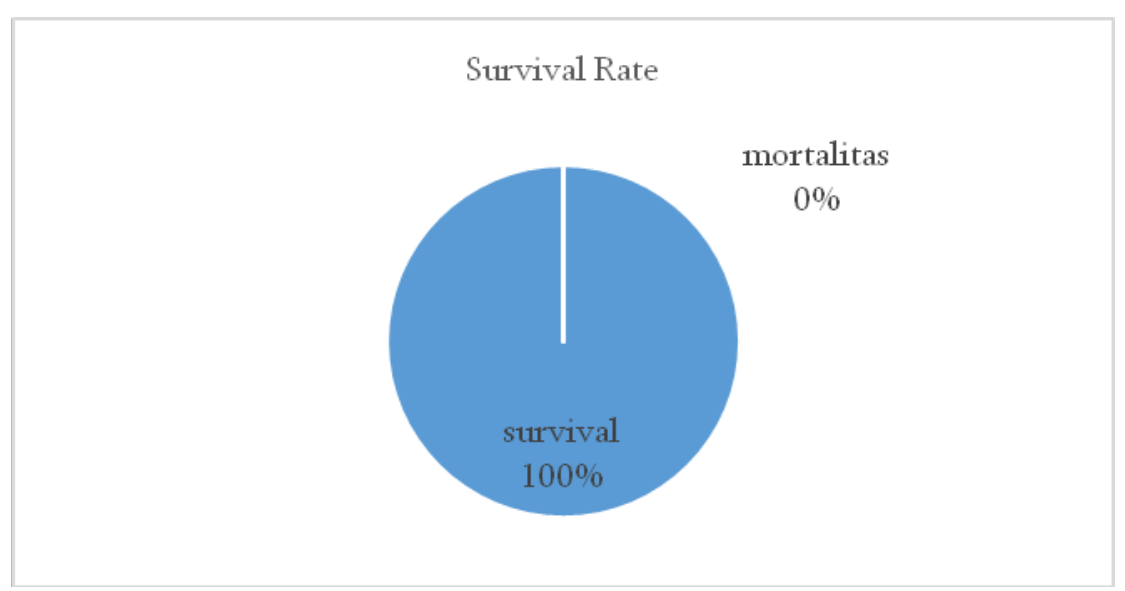

Gambar 3 Diagram Persentase Survival Rate

Setelah tiga puluh hari penelitian, ikan yang dipelihara di dalam filter tank memiliki nilai SR sebesar $100 \%$. Nilai ini menunjukkan bahwa 15 ekor ikan clownfish yang hidup mendapatkan suplai makanan yang cukup selama 30 hari masa perawatan, sesuai penelitian Teuku DAR (2015) menyebutkan bahwa selain kualitas air ada faktor lain yang menunjang kelulushidupan seperti pemberian pakan yang cukup. Angka kematian ikan sebesar $0 \%$ atau 0 ekor karena tidak ada kompetisi makanan antara ikan serta lingkungan yang dibuat sesuai dengan kebutuhan ikan. Kelulushidupan sebesar $100 \%$ menunjukkan penggunaan biofilter pada sistem resirkulasi sangat cocok untuk pengembangan budidaya ikan hias air laut di perairan Sibolga.

\section{KESIMPULAN DAN SARAN}

Penggunaan sistem resirkulasi dengan menggunakan filter bio-organic menunjukkan perubahan fisik air yang lebih baik, dengan demikian air bekas budidaya masih bisa digunakan kembali sehingga memperpanjang masa pergantian air. Perlakuan dengan menggunakan filter bioorganic (pecahan karang dan kerikil) juga mampu memberikan ketersedian pakan alami di dalam wadah pengolahan air.

\section{UCAPAN TERIMA KASIH}

Ucapan terimakasih yang sebesar-besarnya kepada Kementerian Riset dan Teknologi/Badan Riset dan Inovasi Nasional, Deputi Bidang Penguatan Riset dan Pengembangan atas dana penelitian yang telah diberikan untuk menyelesaikan penelitian ini. Ucapan terima kasih juga kami sampaikan kepada Sekolah Tinggi Perikanan Sibolga beserta LPPM di dalamnya sebagai instansi dan lembaga yang menfasilitasi kami dalam penelitian ini.

\section{DAFTAR PUSTAKA}

Bahri S, Edi Rudi, Irma Dewiyanti. 2015. Kondisi Terumbu Karang dan Makro Invertebrata di Perairan Ujong Pancu, Kecamatan Peukan Bada, Aceh Besar. Depik, 4 (1): 1-7.

Effendie MI. 1979. Metode Biologi Perikanan. Yayasan Dwi Sri. Bogor.

Effendie MI. 2004. Pengantar Akuakultur. Penebar Swadaya. Jakarta.

Fauzia SR, Sugeng HS. 2020. Resirkulasi Air untuk Optimalisasi Kualitas Air Budidaya Ikan Nila Nirwana (Oreochromis niloticus). Jurnal Pusat Inovasi Masyarakat, 2(5): 887-892 
Febriwahyudi CT, Hadi W. 2012. Resirkulasi Air Tambak Bandeng dengan Slow Sand Filter. Jurnal Teknik Pomit, 1(1): 1-5.

Isroni W, Setyawati D, Maulida N. 2019. Studi Komunitas Bakteri pada Sistem Resirkulasi pada Budidaya Lele Dumbo (Clarias gariepinus). Journal of Aquaculture and Fish Health, 8(3): 159166.

Lesmana DS. 2016. Kualitas Air Untuk Ikan Hias Air Tawar. Penebar Swadaya. Jakarta.

Muhammad F, Adhar S, Ezraneti R. 2017. Efektivitas Penggunaan Ijuk, Jerami Padi dan Ampas Tebu sebagai Filter Air pada Pemeliharaan Ikan Mas Koki (Carassius auratus). Acta Aquatica, 4(1): 37-43.

Purnawan S. 2015. Kajian Awal Granulometri pada Kawasan Lamun dan Terumbu Karang: Studi Kasus di Gugusan Pulau Pari, Kepulauan Seribu. Depik, 4(2): 107-114.

Rizky TDA, Riri E dan Saiful Adhar. 2015. Pengaruh Media Filter Pada Sistem Resirkulasi Air Untuk Pemeliharaan Ikan Koi (Cyprinus carpio L). Acta Aquatica, 2(2): 97-100.

Samsundari S, Ganjar adhy Wirawan. 2019. Analisis Penerapan Biofilter Dalam Sistem Resirkulasi terhadap Mutu Kualitas Air Budidaya Ikan Sidat (Anguilla bicolor). Jurnal Gamma, 8(2): 86-97.

Sudjana. 2018. Desain dan Analisis Eksperimen. Edisi II. Tarsito. Bandung.

Thesiana L dan Pamungkas A. 2015. Uji Performansi Teknologi Recirculating Aquaculture System (RAS) terhadap Kondisi Kualitas Air pada Pendederan Lobster Pasir (Panulirus homarus). Jurnal Kelautan Nasional, 10(2):65-73.

Widyantoro W, Sarjito, Harwanto D. 2014. Pengaruh Pemuasaan terhadap Pertumbuhan dan Profil Darah Ikan Lele Dumbo (Clarias gariepinus) pada Sistem Resirkulasi. Journal of Aquaculture Management and Technology, 3(2): 103-108. 